\begin{tabular}{l|c|l}
\hline \hline Biological and & Vol. 5(2): 176-193, 2021 & $\begin{array}{l}\text { ISSN: 2002-6153 } \\
\text { Biol. Appl. Environ. Res. } \\
\text { www.baerj.com } \\
\text { editor@ } \text { baerj.com }\end{array}$ \\
\hline
\end{tabular}

\title{
Effect of Bacillus polymyxa as Wild or Mutant by UV and Diagnosed with PCR on the Available Phosphate Fertilizer in Calcareous Soils and Growth Yield of Corn (Zea mays L.)
}

\author{
Zainab K. Hassan \& Alaa M. Khairallah* \\ Department of Soil Sciences and Water Resources, College of Agriculture, \\ University of Basrah, Basrah, Iraq \\ *Corresponding author: alkazrajy777777@gmail.com
}

\begin{abstract}
An agricultural experiment was conducted to study the effect of corn seeds inoculation with mutant, wild or mixed of them together of locally isolate of Bacillus polymyxa on the availability of phosphorus, growth and yield of corn (Zea mays L.) when it was planted in silty clay and loamy sand soils with the addition of four levels of triplsuperphosphate fertilizer $(0,50,75$ and 100 $\mathrm{kg} \mathrm{p} / \mathrm{ha}$ ). B. polymyxa isolate was exposed to UV rays for 60 minutes to obtain mutagenic bacteria. Results showed that inoculation with wild isolate with 75 or $100 \mathrm{~kg} \mathrm{p} / \mathrm{ha}$ gave the best value for plant height, shoot dry weight, phosphorus concentration in the vegetative part and available phosphorus in the soil after planting. Inoculation with mutagenic isolate bacteria gave the value of $69.37 \mathrm{~cm}, 6 \mathrm{~g} / \mathrm{pot}, 43.49 \mathrm{mg} / \mathrm{pot}$ and $27.52 \mathrm{mg} / \mathrm{kg}$ soil for plant height, shoot dry weight, phosphorus absorbed in vegetative part and available phosphorus, respectively when it planted in loamy sand or silty clay soil. On the other hand, the percentage of increase of the effect of phosphate fertilization levels was $47.82 \%, 39.70 \%, 75.53 \%$ and $73.46 \%$ in loamy sand soil and $46.74 \%, 56.96 \%$, $85.33 \%$ and $53.12 \%$ in silty clay soil, respectively.
\end{abstract}

Keywords: Sustainable agriculture, Bacillus polymyxa, Biofertilizers, Mutagenesis

\section{Introduction}

In view of the steady increase in population numbers, which is expected to reach nine billions within the year 2025, the provision of quantities of food, especially strategic crops such as grains is required. This in return needs to provide good scientific management of soil and water. Fertilization is one of the most important requirements for the success of the agricultural process and ensuring good growth. It has an acceptable economic return.

Phosphate fertilization tops the fertilization process after nitrogen because its phosphorus is of great importance in plant life as it enters in the synthesis of nucleic acids that play a major role in the plant's enzymatic reactions such as DNA, RNA, tRNA and Ribosomal RNA as well as in the synthesis of enzymes 
necessary for energy reactions, including respiration and plant photosynthesis (Mengel \& Kirkby, 2001). Phosphate fertilization in soils generally and calcareous soils is exposed to several obstacles that decrease its availability to the plant due to the presence of calcium and calcium carbonates in addition to the alkalinity $\mathrm{pH}$ of the soil. Some studies have shown that the efficiency of phosphate fertilizers does not exceed 50\% (Haran, 2019). This prompted studies and research since ancient times to use natural biological inoculation present in the area of root growth, such as bacteria, fungi, algae and others with a highly specialized ability to convert phosphorous added, or already present in the soil from a precipitated form to a soluble form available for absorption by the plant through several mechanisms including the secretion of organic acids, such as lactic acid, citric acid, oxalic acid and others, or through excretion of mineral acids (Al-Zougbi et al., 2007).

The biological fertilization has proven its efficiency in increasing the efficiency of phosphorus available for plants (Mustafa, 2019). Adding biological inoculation to the soil improves its physical, chemical and fertility properties, including phosphorous and nitrogen availability of micro-nutrients and the ability of the soil to retain water (Al-Mousawi et al., 2017). On this basis, biotechnological studies have sought to develop the performance and efficiency of these organisms present in the soil by a change in the genetic material of the nucleotides on the DNA strand, which is known as genetic mutations that aim to stimulate the secretion of decomposing enzymes, hormones and organic acids (Baker et al., 2019). Some recent biotechnology studies showed that mutagenic and genetically improved bacteria produce many metabolites, such as cytokinins and riboflavin as well as phytohormones such as gibbrllin and in more quantities than normal bacteria. This is as a result of induced mutations that led to an improvement in its functional performance and consequently the growth of the shoots and roots and its extension number for water and the nutrients present in the soil solution including the phosphorous (Jabbar, 2018).

Jasim \& Thiab (2009) showed that improving and developing the efficiency of Pseudomonas aeruginosa in the production of alginate (a product of alginic acid) after exposure to ultraviolet rays of $10,8,6,4$ and $2 \mathrm{~J} / \mathrm{m}$ indicated that mutating bacteria, with ultraviolet rays, led to an increase in their ability to produce alginate by obtaining continuous bacterial mutations in its high productivity of lignite compared to normal isolates. Baker et al. (2019) conducted their study for quantitative multiplication of the two isolates, the two local mutagens Beauveria bassiana and Metarhizium anisopliae. They indicated the improvement of their biological efficiency with ultraviolet rays. Abbas \& Hameed (2006) also indicated the improvement of the production of indole acetic acid, from two mutated isolates of Trichoderma harzianum by using ultraviolet rays. Improving the productivity of mutagenic isolates and their high ability to secrete the growth regulator IAA was reflected in the biological evaluation of wheat seeds and maize. This led to an increase in the rates of seedling growth index/ $\mathrm{cm}$ in a highly significant manner. Also, the mutagenic isolates tolerated high concentrations of the fungicide which reached $1000 \mathrm{ppm}$ compared to the normal non-mutagenic isolate. 
The aims of the present study include the followings:

1- Explain the role of inoculation with $B$. polymyxa, locally mutated with UV rays as well as the role of regular inoculation with wild and mutagenic bacteria in increasing the availability of phosphorus from superphosphate fertilizer, and its reflection in improving the fertile level of loamy sand and silty clay soils to increase yield of corn (Zea mays L.)

2- Explain the role of biotechnology in increasing the fertility level of the soil by using of molecular genetics technology and its role in developing the efficiency of bacteria, reducing the dose of mineral phosphate fertilization and avoiding the addition of material burdens for farmers as well as its negative effects on soil health.

\section{Materials and Methods}

Plants and rhizosphere soil samples were collected from different farms and regions within the geographical area of Basrah Province to isolate B. polymyxa depending on the cultural and biochemical characteristics. Approximately two g of soil was scraped from the roots of each sample and deposited into sterile tubes containing $10 \mathrm{ml}$ of sterile deionized (DI) water. Each test tube was vortexed thoroughly and a series of $1 / 10 \mathrm{ml}-1 / 10^{8} \mathrm{ml}$ was completed preparation, put two $\mathrm{g}$ of soil in first test tube $1 / 10 \mathrm{ml}$ and shacked well for three minutes. One $\mathrm{ml}$ from $1 / 10 \mathrm{ml}$ to $1 / 10^{2} \mathrm{ml}$ was transferred while continuing to shake and this process was repeated until reaching to $1 / 10^{8} \mathrm{ml}$. The Pikovskaya (PVK) media contained (in g/l) 10 glucose, 0.5 yeast extract, $0.5\left(\mathrm{NH}_{4}\right) 2 \mathrm{SO}_{4}, 0.1 \mathrm{MgSO}_{4} .7 \mathrm{H}_{2} \mathrm{O}, 5 \mathrm{Ca}_{3}$ $\left(\mathrm{PO}_{4}\right)^{2}, 0.2 \mathrm{KCl}, 0.002 \mathrm{MnSO}_{4} .2 \mathrm{H}_{2} 0,0.002 \mathrm{FeSO}_{4} .7 \mathrm{H}_{2} \mathrm{O}$ and $15 \mathrm{~g}$ agar. After that, this medium was put in an autoclave at a temperature of $121^{\circ} \mathrm{C}$ and a pressure of 15 bar. One $\mathrm{ml}$ from each $1 / 10^{5} \mathrm{ml}, 1 / 10^{6} \mathrm{ml}, 1.10^{7} \mathrm{ml}$ and $1.10^{8} \mathrm{ml}$ was taken and put in Petri dishes contained with PVK media and incubated at $30{ }^{\circ} \mathrm{C}$ for up to seven days. After that, bacteria colonies were purified by mapping them in a new PVK media depending on the cultural and biochemical characteristics.

Mutating of bacterial isolates by UV rays was done by taking one dish from each pure bacterial isolate. As the dish was opened, it was exposed to ultraviolet rays away, $30 \mathrm{~cm}$ from the light source. The wavelength was $254-255 \mathrm{~nm}$. Then, the dishes were incubated after their exposure to different periods of radiation time (15, 30, 45 and 60 minutes). The ultraviolet was then taken in a volume known as a loop full of UV treated isolates were transferred to a solid slanted culture media (nutrient agar). It was incubated for 3-4 days at a temperature of 30 ${ }^{\circ} \mathrm{C}$.

\section{Characterization of Isolates}

All isolates were genotypically characterized by cloning and sequencing the $16 \mathrm{~S}$ rRNA. Briefly, the genomic DNA from a pure culture of each isolate was extracted and purified for PCR amplification of the 16S rRNA (Fig. 1) notes bundle of DNA extraction from bacteria dissolving phosphate which confirm purity by Nano Drop 
at percentage A280/A260 for ten isolate, it was 1.8 as aguid to the best purity, and bundle amplification of PCR was a molecular weight $308 \mathrm{bp}$.

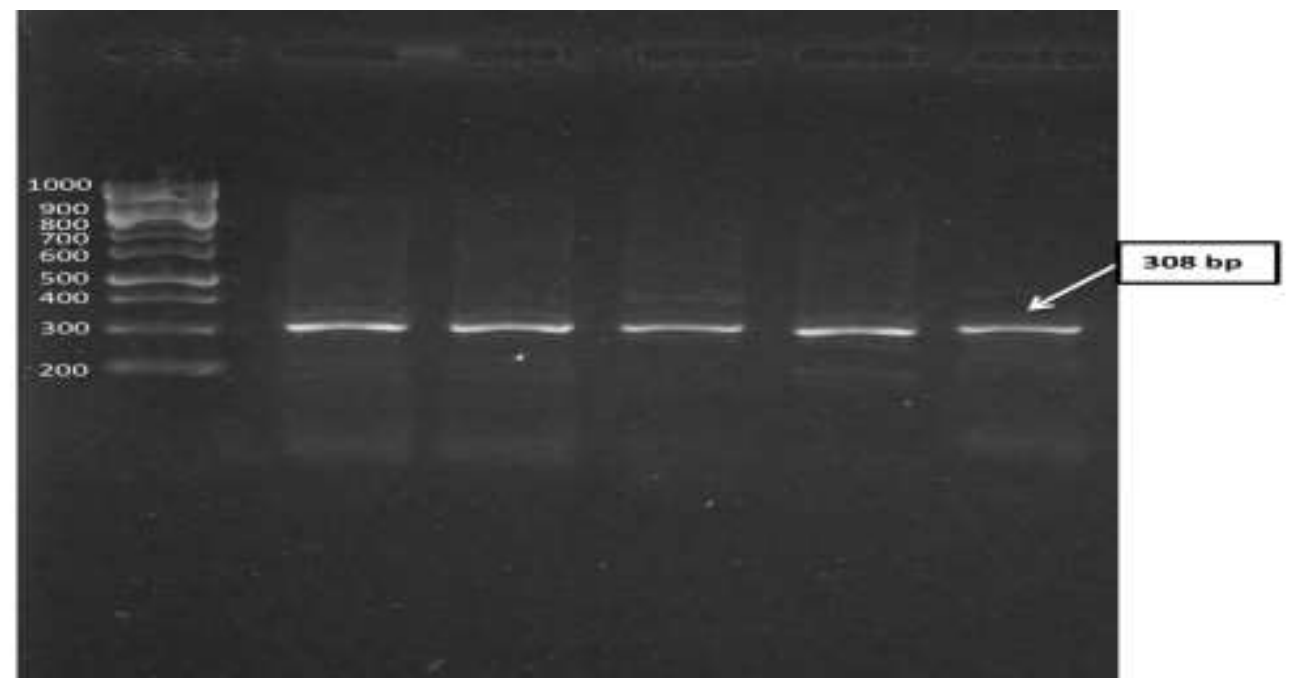

Figure 1: Amplification products of the DNA of the piece $308 \mathrm{bp}$ to $B$. polymyxa, electrophoresis product PCR.

Isolate of wild or mutagenic of $B$. polymyxa were grown in nutrient agar media in test tubes and harvested after 24 hours with concentration of $1.5 \times 10^{8} \mathrm{cell} / \mathrm{ml}$. The isolates were grown in the PVK liquid medium and measured by spectrophotometer for each inoculums and added to $150 \mathrm{ml}$ sterile distilled water to prepare the inoculum. The inoculation treatment was divided into four sections; without inoculation (B0), inoculation with wild isolate (BW), inoculation with mutagenic isolate (BM) and inoculation with both wild isolates and mutagenic (BWM). The purpose of mixing two inoculation together was to reach the maximum dissolving amount and reduce added mineral phosphate fertilizer. After sterilizing corn seeds more than once with $95 \%$ ethyl alcohol and washing three times with distilled water, they were wet with Arabic gum then, inoculated and well mixed with the inoculum and prepared for the pot experiment.

The pot experiment was conducted on two types of soils of different textures. The first soil represented a loamy sand and under the order Pasamments and order Entisol taken from a farm in the Al-Barjisia area, Al-Zubair District in Basrah Province. The second soil was a silty clay, classified under a super group Typic torri fluvents (Al-Atab, 2008), and the latter soil was taken from a farm in the Hamdan area, Abu Al-Khasib District in Basrah Province.

Each soil was air dried, grinded and pass through a sieve of $2 \mathrm{~mm}$ to determine the physical, chemical and biological properties of the two soils before planting, as shown in Table 1.

Measurements of $\mathrm{pH}$, EC, organic matter, CEC, sodium, potassium and dissolved sulfate ions, available potassium and phosphorous were done according to Page et al. (1982), while calcium, magnesium, carbonates, bicarbonates and 
dissolved chloride ions according to Richards (1954) and minerals carbonate according to Jackson (1985). Available nitrogen was according to Bremner \& Edwards (1965). Selecting the separations of soil texture, total bacteria in soil, fungi numbers, and numbers of phosphate-dissolving bacteria was according to Black (1965).

Table 1: Some physical, chemical and biological characteristics of the two types of soils before planting.

\begin{tabular}{|c|c|c|c|c|}
\hline \multicolumn{2}{|c|}{ Characteristics } & Unit & $\begin{array}{c}\text { Al-Burjisia } \\
\text { soil }\end{array}$ & $\begin{array}{c}\text { Abu Al-Khasib } \\
\text { soil }\end{array}$ \\
\hline \multicolumn{3}{|l|}{$\mathrm{pH}$} & 7.1 & 7.5 \\
\hline \multicolumn{2}{|c|}{ Electrical conductivity(EC) } & $\mathrm{Ds} / \mathrm{m}$ & 4.5 & 5.6 \\
\hline \multicolumn{2}{|c|}{ Cationic exchange capacity(CEC) } & $\mathrm{C} \mathrm{mol}^{+} / \mathrm{kg}$ soil & 5.39 & 10.67 \\
\hline \multicolumn{2}{|c|}{ Total carbonates } & $\mathrm{g} / \mathrm{kg}$ & 125.63 & 356 \\
\hline \multicolumn{2}{|c|}{ Organic matter } & $\mathrm{g} / \mathrm{kg}$ & 1.45 & 2.41 \\
\hline \multicolumn{5}{|c|}{ Dissolved cation ions } \\
\hline \multicolumn{2}{|l|}{ Calcium } & \multirow{4}{*}{$\mathrm{Mmol} / \mathrm{l}$} & 9.00 & 11.06 \\
\hline \multicolumn{2}{|c|}{ Magnesium } & & 5.7 & 7.12 \\
\hline \multicolumn{2}{|c|}{ Potassium } & & 1.20 & 3.10 \\
\hline \multicolumn{2}{|l|}{ Sodium } & & 9.58 & 12.02 \\
\hline \multicolumn{5}{|c|}{ Dissolved negative ions } \\
\hline \multicolumn{2}{|c|}{ Carbonates } & \multirow{4}{*}{$\mathrm{Mmol} / \mathrm{l}$} & 0.00 & 0.00 \\
\hline \multicolumn{2}{|c|}{ Bicarbonate } & & 2.10 & 5.09 \\
\hline \multicolumn{2}{|l|}{ Sulfates } & & 14.44 & 16.10 \\
\hline \multicolumn{2}{|l|}{ Chloride } & & 6.11 & 9.26 \\
\hline \multicolumn{2}{|c|}{ Total nitrogen } & \multirow{4}{*}{$\mathrm{Mg} / \mathrm{kg}$} & 0.052 & 0.072 \\
\hline \multirow{3}{*}{$\begin{array}{l}\text { Available } \\
\text { elements }\end{array}$} & Nitrogen & & 0.015 & 0.025 \\
\hline & Phosphorus & & 0.010 & 0.012 \\
\hline & Potassium & & 0.055 & 0.075 \\
\hline \multicolumn{5}{|c|}{ Soil texture separations } \\
\hline \multicolumn{2}{|l|}{ Sand } & \multirow{3}{*}{ Gk/g soil } & 679.63 & 30.2 \\
\hline \multicolumn{2}{|l|}{ Silt } & & 200.15 & 437.70 \\
\hline \multicolumn{2}{|l|}{ Clay } & & 120.22 & 532.1 \\
\hline \multicolumn{3}{|c|}{ Class texture } & Loamy sand & Silty clay \\
\hline \multicolumn{2}{|c|}{ Total bacteria } & \multirow{3}{*}{ CFU/g soil } & $10^{6} \times 2.3$ & $10^{6} \times 5.4$ \\
\hline \multirow{2}{*}{\multicolumn{2}{|c|}{$\begin{array}{l}\text { Fungi } \\
\text { Phosphate diss }\end{array}$}} & & $10^{4} \times 2.8$ & $10^{4} \times 25.57$ \\
\hline & & & $10^{6} \times 0.20$ & $10^{6} \times 3.51$ \\
\hline
\end{tabular}

\section{Experimental Factors}

The study included the following factors:

Two soil type (loamy sand and silty clay soil)

Four phosphate fertilizer levels $(0,50,75$ and $100 \mathrm{~kg} \mathrm{p} / \mathrm{ha})$

Four inoculums types (without inoculation B0, inoculation with wild bacteria BW, inoculation with mutagenic bacteria BM and inoculation with mixed of BW+BM. Three replicates, so the total experimental units $=96$. 
Half of the dose of urea was added according to the recommendation of fertilizers. Adding the urea fertilizer ( $46 \%$ nitrogen) was with a recommendation of $300 \mathrm{~kg} \mathrm{~N} / \mathrm{ha}$ and by $0.35 \mathrm{~g} /$ pot with two parts; one part before planting and the other part a month after planting. Potassium fertilizer, in the form of potassium sulfate $\left(43 \% \mathrm{~K}_{2} \mathrm{O}\right)$ was with a recommendation of $180 \mathrm{~kg} \mathrm{~K} / \mathrm{ha}$ at $0.19 \mathrm{~g}$ pot/ha, as a one dose before planting. The levels of phosphate fertilization was added as a one dose before planting. It was $0,50,75$ and $100 \%$ of the fertilizer recommendation of $130 \mathrm{~kg} \mathrm{P} / \mathrm{ha}$ triple superphosphate fertilizer (P\%21). So, the phosphate fertilization treatments became as follows:

- $0 \%$ without any addition of triple superphosphate fertilizer.

$-50 \%$ with fertilizer at $0.034 \mathrm{~g} /$ pot.

$-75 \%$ with fertilizer at $0.039 \mathrm{~g} / \mathrm{pot}$.

- $100 \%$ with fertilizer at $0.068 \mathrm{~g} /$ pot.

After 60 days of planting, the plants were harvested. The characteristics which were studied included plant height, dry weight of vegetative part, amount of phosphorous absorbed in vegetative part and available phosphorous in soil after planting. These were estimated according to Page et al. (1982). Numbers of $B$. polymyxa CFU in the soil, after planting, was according to Black (1965).

\section{Statistical Analysis}

The experiment was statistically designed with three replications as a factorial experiment by using Complete Randomized Design (CRD). Analyzing the data was by using the statistical program (SPSS). The averages of the coefficients was compared by using the test of the least significant difference rate (RLSD) at a probability level of 0.05 (Al-Rawi \& Khalafallah, 2000).

\section{Results and Discussion Plant Height (cm)}

The results of Table 2 and the statistical analysis indicated that there was a significant effect (LSD 0.05) for the inoculation with B. polymyxa, whether wild, mutagenic or mixed together, and phosphate fertilization level in the plant height in the loamy sand and silty clay calcareous soils. This is because the added phosphates alone are exposed to the process of adsorption and sedimentation, and their conversion into insoluble compounds that are not beneficial to the plant, as when the bacteria dissolving phosphates added, plant was maximum beneficial from the added mineral fertilizer. In loamy sand soils, an increase in the rate of plant height was from $45.75 \mathrm{~cm}$ when not inoculated (B0) to $58.52,69.37$ and $79.35 \mathrm{~cm}$ when inoculated with wild, mutagenic bacteria or mixing them together, respectively with an increase of $73.8 \%$ compared to non-inoculation treatment (B0). The statistical analysis indicated that adding levels of phosphate fertilization (P0, P50, P75 and P100) had a significant effect on the rate of plant height in sandy soils, as the rate was increased from $50.60 \mathrm{~cm}$ at the level P0 to $58.45,68.93$ and $74.80 \mathrm{~cm}$ at the levels of P50, P75 and P100, respectively with an increase of $47.82 \%$ compared to the comparison level $\mathrm{P} 0$. 
The statistical analysis showed that there was a significant effect of the interaction between the type of inoculation and the level of phosphorus fertilizer. The highest value reached $95.96 \mathrm{~cm}$ in the treatment of BWM with a fertilizer level of P100 in comparison with the lowest value for the treatment without inoculation and without fertilizer, was $36.46 \mathrm{~cm} /$ pot. As for clay soil, the results showed a significant effect of inoculation with bacteria whether wild or mutagenic, or mixing them together in the effect on the rate of plant height. It was increased from 55.54 $\mathrm{cm} /$ pot when compared (non- inoculation B0) to $68.23,77.20$ and $89.06 \mathrm{~cm} /$ pot for inoculation whether wild or mutagenic, or mixing them together, respectively with an increase of $60.35 \%$ compared to non- inoculation (B0). There was a significant effect on the rate of plant height with increasing levels of phosphate fertilizer in clay soils. The rate of plant height increased from $57.23 \mathrm{~cm}$ at P0 level (comparison) to $71.26,79.80$ and $83.98 \mathrm{~cm}$ levels for P50, P75 and P100, respectively with an increase of $46.74 \%$ compared to no addition (P0). Also, it was noticed that there was a significant effect of the bilateral interference between the type of inoculation and the level of phosphorus fertilizer as it reached the highest value of $101.8 \mathrm{~cm}$ in the inoculation treatment BWM with the fertilizer level P75 compared to the lowest value when it compare with the treatment without inoculation and without phosphate fertilizer as it reached $45.1 \mathrm{~cm}$.

The increase in plant height in the treatments of bacterial inoculation whether in loamy sand soil or silty clay soil, may be attributed to the role of these bacteria, by dissolving phosphates and increasing the available of phosphorous as well as its ability to secrete stimulant substances such as phenols, gibberellins and cytokines that encourage growth due to increase in the absorption of nitrogen, phosphorus and potassium will then result in an increase in plant height (Mustafa, 2019).

As inoculated treatments with bacteria mutagenic by UV and genetically improved, the plant height values exceeded compared to the inoculated treatments with wild bacteria in sandy and clay soils. This may be attributed to the occurrence of mutations induced in bacteria, which improved its performance, effectiveness and metabolic processes. Hence, it encourages the absorption of nutrients, especially phosphorous, which contributes to improving plant growth, functional performance and encouraging the absorption of water and various nutrients from the soil. These are positively reflected on plant height and growth (Turki et al., 2010). The secretion of growth regulators in the soil plays an important role in plant cell division, elongation and stimulation of root capillaries on nutrient absorption (Richa et al., 2007). The superiority of plant height values in the inoculated treatments by wild and mutagenic together due to the increase in bacterial density, whether normal or mutagenic, in the rhizosphere soil as well as the ability of nonmutagenic and mutagenic bacteria to dissolve phosphate and secrete growth regulators in a good way and in large quantities which improve soil fertility and increase plant growth (Jabbar, 2018). 
Table 2: The effect of inoculation with B. Polymyxa wild, mutagenic, mixing them together and levels of phosphate fertilization on the plant height of the corn $(\mathrm{cm})$.

\begin{tabular}{|c|c|c|c|c|c|}
\hline \multicolumn{6}{|c|}{ Loamy sand soil } \\
\hline \multirow{2}{*}{$\begin{array}{c}\text { Bacterial } \\
\text { inoculation }\end{array}$} & \multicolumn{4}{|c|}{ Levels of phosphate fertilization } & \multirow[t]{2}{*}{ Rate } \\
\hline & P0 & P50 & P75 & P100 & \\
\hline B0 & 36.46 & 46.43 & 43.5 & 56.6 & 45.75 \\
\hline BW & 45.6 & 55.16 & 65.33 & 68 & 58.52 \\
\hline BM & 57.36 & 69.86 & 71.96 & 78.33 & 69.37 \\
\hline BWM & 53.03 & 72.18 & 94.96 & 95.96 & 79.35 \\
\hline Rate & 50.60 & 58.45 & 68.93 & 74.80 & \\
\hline \multicolumn{6}{|c|}{ Silty clay soil } \\
\hline \multirow{2}{*}{$\begin{array}{l}\text { Bacterial } \\
\text { inoculation }\end{array}$} & \multicolumn{4}{|c|}{ Levels of phosphate fertilization } & \multirow[t]{2}{*}{ Rate } \\
\hline & $\mathrm{P} 0$ & P50 & P75 & P100 & \\
\hline B0 & 45.1 & \multirow{2}{*}{$\begin{array}{l}51.26 \\
66.1\end{array}$} & 95.1 & 66.7 & 55.54 \\
\hline BW & 55.36 & & 69.63 & 81.83 & 68.23 \\
\hline BM & 62.83 & 78.56 & 88.7 & 87.73 & 77.20 \\
\hline BWM & 65.66 & 89.13 & 101.8 & 99.6 & 89.06 \\
\hline Rate & 57.23 & 71.26 & 79.80 & 83.98 & \\
\hline \multirow{4}{*}{ LSD 0.05} & \multicolumn{2}{|c|}{ Texture } & 0.171 & $\begin{array}{c}\text { Texture } \times \text { Type } \\
\text { inoculation }\end{array}$ & ns \\
\hline & \multicolumn{2}{|c|}{ Inoculation type } & 0.342 & Texture $\times$ P Level & ns \\
\hline & \multicolumn{2}{|c|}{ P Level } & 0.342 & $\begin{array}{l}\text { Type inoculation } \\
\times \text { P Level }\end{array}$ & 1.441 \\
\hline & \multicolumn{3}{|c|}{ Texture $\times$ inoculation type $\times$ P Level } & \multicolumn{2}{|c|}{3.180} \\
\hline
\end{tabular}

The increase in plant height, when inoculated with wild or mutagenic bacteria or together, whether in loamy sand or silty clay soil by increasing levels of phosphate fertilizer addition is may be due to the direct role of phosphorus when it is available in the fertilizer as well as to its absorption by the plant and its role within the plant from the division of plant cells and the spread of roots and their absorption of nutrients and biological building processes through energy compounds and physiological processes, and hence an increase in plant growth and height (Amruth et al., 2017).

\section{Shoot Dry Weight (g/pot)}

Table 3 and the statistical analysis indicated that there was a significant effect (LSD 0.05) for by the inoculation of B. polymyxa whether wild, mutagenic or mixed together, and phosphate fertilization levels in the dry weight of the vegetative part of the maize in the loamy sand and silty clay calcareous soils. In sandy soils, an increase in the average dry weight of the vegetative fraction ranged from $3.28 \mathrm{~g} /$ pot when not inoculated (B0) to 5.15, 6 and $6.04 \mathrm{~g} /$ pot when inoculation with wild, mutagenic bacteria or mixing them together, with an increase of $84.14 \%$ compared to the non-inoculation treatment (B0). 
The addition of phosphate fertilizer (P0, P50, P75 and P100) had a significant effect on the average dry weight, as the rate increased from $4.13 \mathrm{~g} / \mathrm{pot}$ at the $\mathrm{P} 0$ level to 5.10, 5.46 and $5.77 \mathrm{~g} / \mathrm{pot}$ at the levels of P50, P75 and P100, respectively with an increase of $39.70 \%$ compared to the control level P0. The statistical analysis showed that there was no significant effect of the bilateral interaction between the type of bacterial inoculation and the levels of phosphate fertilizer.

For silty clay soil, the results showed a significant effect of inoculation with bacteria, whether wild or mutagenic, or mixing them together, in the effect on the rate of dry weight of the vegetative part which increased from $4.48 \mathrm{~g} / \mathrm{pot}$ when compared with non-inoculation (B0) to 5.91, 6.97 and $8.14 \mathrm{~g} / \mathrm{pot}$ for the inoculation, whether wild or mutagenic or mixing them together, respectively with an increase of $81.69 \%$, compared to the non- inoculation (B0). Also, adding levels of phosphate fertilization (P0, P50, P75 and P100) had a significant effect on the dry weight rate of the vegetative part, increased the rate of dry weight of the vegetative part from $4.88 \mathrm{~g} / \mathrm{pot}$ at the level $\mathrm{P} 0$ (comparison) to 5.62, 7.34 and 7.66 $\mathrm{g} /$ pot for the levels of P50, P75 and P100, respectively with an increase of 56.96\% compared to no addition (P0). The results showed that there was no significant effect of the interaction between the type of bacterial inoculation and the levels of phosphate fertilizer.

The reason of increasing the dry weight in the vegetative part of the inoculated treatments with wild bacteria, whether in loamy sand or silty clay soil, may due to the ability of $B$. polymyxa to dissolve phosphorus through plant secretions of metabolites in the root area and in the role of organisms dissolving phosphates and increasing the readiness of phosphorous or to form hydroxyl acids produced by bacteria dissolving phosphates. Such results are in agreement with Hassan (2011) and Jabbar (2018). The values of dry weight of the vegetative part were increased in the treatments inoculated with mutagenic bacteria, compared to the treatments inoculated with wild bacteria. This may be attributed to the mutations induced in the $B$. polymyxa that led to an improvement in its ability to dissolve phosphate as a result of its functional activity, especially under conditions of calcareous soils that lack in its available phosphorus. The increase in the dry weight in the vegetative part of the treatments inoculated with mutagenic bacteria indicated an increase in the secretion of growth regulators that promote hydrolytic enzymes which are reflected in the decomposition of the food stock (Hassan, 2015). The results showed the superiority of the inoculated treatments, with the wild and mutagenic together, in the dry weight of the vegetative part of the maize compared to the single inoculation. This may due to the high density of bacteria that have vital activities in the rhizosphere and the ability of the dissolving phosphate bacteria to increase the availability of the nutrients $(\mathrm{N}, \mathrm{P}, \mathrm{Zn}, \mathrm{Cu}, \mathrm{K}, \mathrm{S}, \mathrm{Mn}, \mathrm{Ca}$ and $\mathrm{Fe}$ ) which are of great benefit to the plant. The joint inoculation with levels of mineral fertilizer contributed to increasing the dry weight in the corn and because B. polymyxa, wild and mutagenic together, encouraged the production of organic acids which reduced soil $\mathrm{pH}$ and thus increased the availbility of important plant nutrients such as nitrogen and potassium phosphorous (Naser, 2016). 
Table 3: The effect of inoculation with B. polymyxa wild, mutagenic, mixing them together and levels of phosphate fertilization in the shoot dry weight.

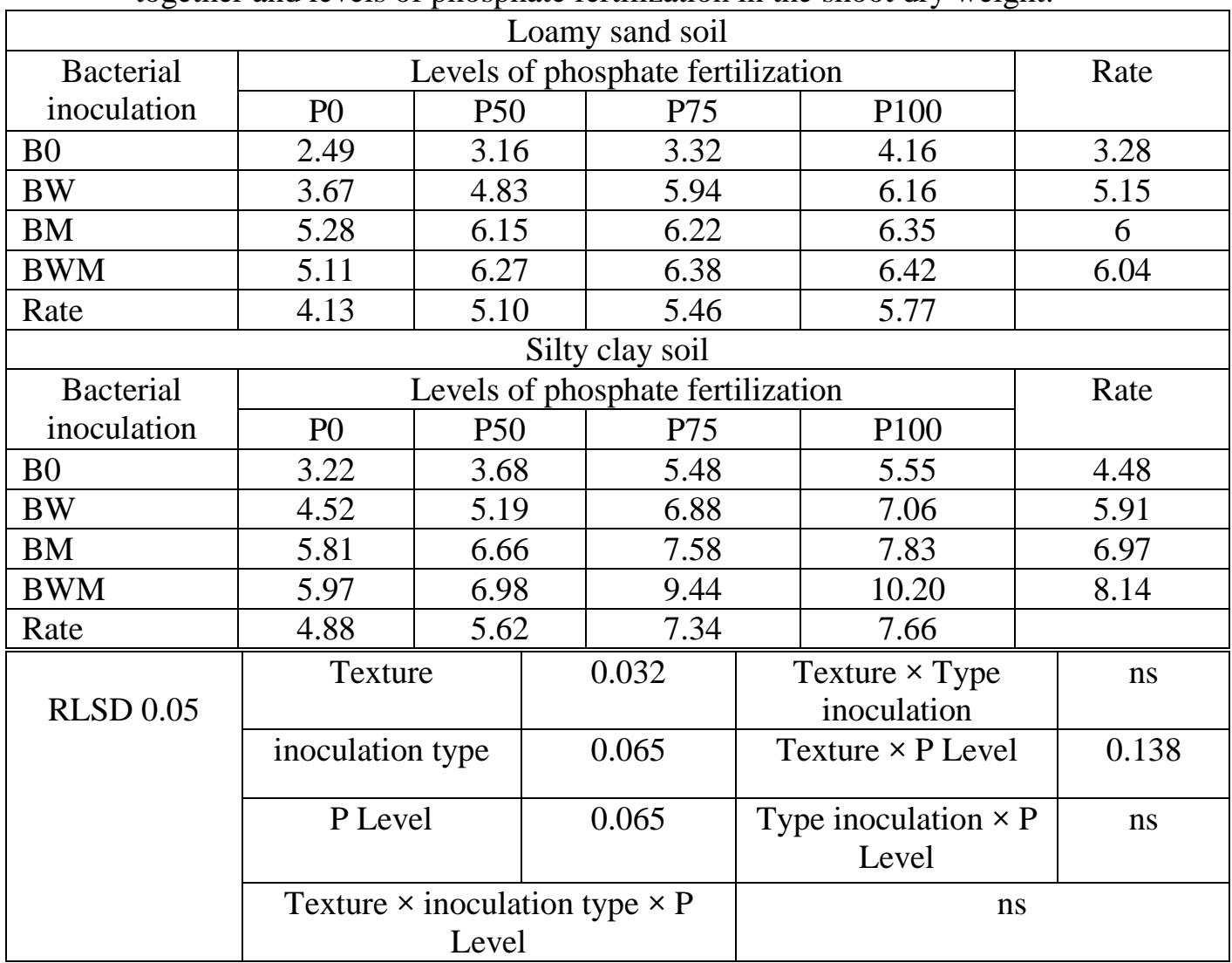

The increase in the dry weight of the vegetative part of the plant by increasing the levels of added phosphate fertilizer is due to the increase in the amount of available phosphorous in the soil, which led to the formation of a good root group able to absorb nutrients and transport them to the vegetative parts of the plant (Mustafa, 2019).

\section{Uptake Phosphate of Shoot Plant (mg/pot)}

Table 4 and the statistical analysis indicated that there was a significant effect (RLSD 0.05) of inoculation with B. polymyxa, whether wild, mutagenic or mixed together. In loamy sand soil, the increase in the amount of phosphorus absorbed in the vegetative part was from $24.10 \mathrm{mg} / \mathrm{pot}$ when not inoculated (B0) to 29.03, 43.49 and $47.37 \mathrm{mg} /$ pot when inoculation with wild, mutagenic or mixing bacteria together, with an increase of $96.63 \%$ compared to the non-inoculation treatment (B0). Adding levels of phosphate fertilizer (P0, P50, P75 and P100) had a significant effect on the rate of phosphorus absorption in the vegetative part, as the rate increased from $18.84 \mathrm{mg} / \mathrm{pot}$ at the level P0 to 29.99, 43.27 and $51.91 \mathrm{mg} / \mathrm{pot}$ at levels P50, P75 and P100, respectively with an increase of $75.53 \%$ compared to the control treatment P0. The statistical analysis showed a significant effect of the 
control treatment between the type of inoculation and fertilizer levels of phosphates. The highest value of the absorbed quantity of phosphorus was 68.27 $\mathrm{mg} /$ pot when treating with BWM and level P100, compared to the lowest value when compared to treatment without inoculation and without fertilizer as it reached $9.11 \mathrm{mg} / \mathrm{pot}$.

Silty clay soil showed a significant effect of inoculation with bacteria, whether wild or mutagenic or mixing them together, in affecting the average amount of phosphorus absorbed in the vegetative part. The amount increased from 28.58 $\mathrm{mg} /$ pot when compared (non-inoculation B0) to $37.02,51.59$ and $57.12 \mathrm{mg} /$ pot for inoculation, whether wild or mutagenic or mixing them together, respectively with an increase of $96.86 \%$ compared to non-vaccination (B0). Adding levels of phosphate fertilization (P0, P50, P75 and P100) had a significant effect on the rate of amount of phosphorus absorbed in the vegetative part. The rate amount of phosphorus absorbed in the vegetative part increased from $30.11 \mathrm{mg} /$ pot at the level P0 (comparison) to $38.49,51.03$ and $57.01 \mathrm{mg} /$ pot for P50, P75 and P100, respectively with a percentage increase which reached $85.33 \%$ compared to P0.A significant effect of the bilateral interaction between the type of inoculation and the levels of phosphate fertilizer was shown. The highest value of the amount of absorbed phosphorus reached $71.22 \mathrm{mg} /$ pot when treatment BWM and the level P100 compared to the lowest value for the treatment of without inoculation and without fertilizer $(16.15 \mathrm{mg} / \mathrm{pot})$.

The plant secretions of metabolites in the root area and in the presence of phosphate dissolving bacteria led to the improvement of various soil characteristics as well as the increase of phosphorous solubility. The hydroxyl acids, produced by these bacteria, can be complexed with calcium and increase the availbility of phosphorous as well as reduce soil $\mathrm{pH}$ due to substitution of negatively charged organic acids of phosphorus associated with minerals and oxides which leads to the release of phosphorus into the soil solution. These results agreed with FincheiraRobles et al. (2016) and Amruth et al. (2017).

Values of phosphorus absorbed in the vegetative part of the plant were higher in the treatments inoculated with mutagenic bacteria, compared with treatments wild bacteria. This is attributed to the fact that bacteria dissolve phosphates, mutagenic inoculation increased available phosphorous in the soil and improved growth which led to an increase in the chance of phosphorus uptake by the plant. As showed by Chaichi et al. (2015), increased phosphorous in the vegetative part for the plant by the action of phosphate dissolving bacteria is due to the increase in the area of the root system, which is in greater contact with the phosphate ions, or due to the role of the mutagenic bacteria that dissolve phosphates and produce an active and stable vegetative growth since the beginning of the season. Such production increases the ability of the plant to absorb phosphorous. As the treatments inoculated with wild and mutagenic bacteria together, the results showed an increase in the amount of phosphorus absorbed in the vegetative part of corn, compared to single inoculation. This is may be due to the effect of that the mutagenic bacteria, which genetically improved and reduce the $\mathrm{pH}$ of soil rhizosphere through the secretion of abundant 
and varied quantities of organic acids and growth hormones, in addition to their efficiency in dissolving phosphates, unavailable through acidification, chelation and ion exchange (Al-Taii \& Dhahi, 2014; Jabbar, 2018).

Table 4: The effect of inoculation with B. polymyxa wild, mutagenic and, mixing them together and levels of phosphate fertilization in the absorbed amount of phosphorus (mg/pot) in the vegetative part of corn.

\begin{tabular}{|c|c|c|c|c|c|c|}
\hline \multicolumn{7}{|c|}{ Loamy sand soil } \\
\hline \multirow{2}{*}{$\begin{array}{c}\text { Bacterial } \\
\text { inoculation }\end{array}$} & \multicolumn{5}{|c|}{ Levels of phosphate fertilization } & \multirow[t]{2}{*}{ Rate } \\
\hline & P0 & \multicolumn{2}{|c|}{$\mathrm{P} 50$} & $\mathrm{P} 75$ & $\mathrm{P} 100$ & \\
\hline B0 & 9.11 & \multicolumn{2}{|c|}{19.45} & 28.43 & 39.43 & 24.10 \\
\hline BW & 19.79 & \multicolumn{2}{|c|}{20.95} & 31.86 & 43.55 & 29.03 \\
\hline $\mathrm{BM}$ & 22.69 & \multicolumn{2}{|c|}{39.36} & 52.51 & 65.42 & 43.49 \\
\hline BWM & 23.79 & \multicolumn{2}{|c|}{40.22} & 60.29 & 68.27 & 47.37 \\
\hline Rate & 18.84 & \multicolumn{2}{|c|}{29.99} & 43.27 & 51.91 & \\
\hline \multicolumn{7}{|c|}{ Silty clay soil } \\
\hline \multirow{2}{*}{$\begin{array}{l}\text { Bacterial } \\
\text { inoculation }\end{array}$} & \multicolumn{5}{|c|}{ Levels of phosphate fertilization } & \multirow[t]{2}{*}{ Rate } \\
\hline & P0 & \multicolumn{2}{|c|}{$\mathrm{P} 50$} & $\mathrm{P} 75$ & P100 & \\
\hline B0 & 16.15 & \multicolumn{2}{|c|}{25.02} & 31.11 & 42.06 & 28.58 \\
\hline BW & 25.52 & \multicolumn{2}{|c|}{31.82} & 42.09 & 48.66 & 37.02 \\
\hline BM & 37.19 & \multicolumn{2}{|c|}{45.56} & 57.56 & 66.07 & 51.59 \\
\hline BWM & 40.93 & \multicolumn{2}{|c|}{51.22} & 65.13 & 71.22 & 57.12 \\
\hline Rate & 30.11 & \multicolumn{2}{|c|}{38.49} & 51.03 & 57.01 & \\
\hline \multirow{4}{*}{ RLSD 0.05} & \multicolumn{2}{|c|}{ Texture } & \multicolumn{2}{|l|}{0.060} & $\begin{array}{c}\text { Texture } \times \text { Type } \\
\text { inoculation }\end{array}$ & 0.243 \\
\hline & e inocula & & 0.121 & & < P Level & 0.243 \\
\hline & P L & & 0.121 & & $\begin{array}{l}\text { ilation } \times \mathrm{P} \\
\text { vel }\end{array}$ & 0.486 \\
\hline & Texture & $\begin{array}{l}\text { culat } \\
\text { evel }\end{array}$ & ype $x$ P & & 0.973 & \\
\hline
\end{tabular}

The increase of available phosphorus in the soil with the addition of levels of chemical fertilization, significantly between one level and another, is due to the fact that adding superphosphate fertilizer to the soil increases the chance of dissolving available mineral phosphorus directly. Hence, the presence of small amounts of available phosphorus in the soil increases the chance of its absorption and stabilization. This comes in agreement with Amruth et al. (2017). Sumalatha \& Jebarathnam (2018) who showed that the absorbed amount is a reflection of the dry matter weight and the element concentration in the plant. This is what has been observed in present study, as the increase in weight of dry matter and the concentration of phosphorus in the vegetative part with the levels of phosphate fertilization is reflected in the amount of absorbed phosphorus. Superphosphate fertilizer leads to a decrease in the $\mathrm{pH}$ values of the media, due to its acidic effect, 
as it contains $6 \%$ phosphoric acid when it is manufactured. These results agree with Jabbar (2018).

\section{Available Phosphorus in Soil after Planting (mg.kg/soil)}

Table 5 and the statistical analysis indicated that there was a significant effect (RLSD 0.05) of the inoculation with B. polymyxa, whether wild, mutagenic or mixed together and the levels of phosphate fertilization in available phosphorous in the soil after planting of yellow corn in calcareous loamy sand and silty clay soils.

In loamy sand soil, an increase in the rate of available phosphorus was noticed in the soil from $15.24 \mathrm{mg} / \mathrm{kg}$ soil when not inoculated (B0) to $22.16,27.52$ and 28.79 $\mathrm{mg} . \mathrm{kg} / \mathrm{soil}$. When inoculating with wild, mutagenic bacteria or mixing them together, an increase of $88.91 \%$ compared to the non-inoculation treatment (B0) was noticed. Adding levels of phosphate fertilization (P0, P50, P75 and P100) had a significant effect on the rate of available phosphorus in the soil. The rate increased from $17.15 \mathrm{mg} . \mathrm{kg} / \mathrm{soil}$ at the P0 level to 21.37, 25.45 and $29.75 \mathrm{mg} . \mathrm{kg} / \mathrm{soil}$ at P50, P75 and P100, respectively with an increase of $73.46 \%$ compared to the comparison level P0. The statistical analysis showed that there was no significant differences for the bilateral interaction between the inoculation type and the phosphorus levels on the available phosphorus in the soil after planting.

As for silty clay soil, a significant effect of inoculation with bacteria, whether wild or mutagenic, or mixing them together, in affecting on the rate of available phosphorus in the soil was noticed as it increased from $16.42 \mathrm{mg} . \mathrm{kg} / \mathrm{soil}$ when compared (non-inoculation B0) to $24.34,30.72$ and $32.52 \mathrm{mg} . \mathrm{kg} / \mathrm{soil}$ for inoculation whether wild or mutagenic, or mixing them together, respectively with an increase of $97.05 \%$, compared to non-inoculation (B0). Adding levels of phosphate fertilization (P0, P50, P75 and P100) had a significant effect on the rate of available phosphorous in the soil. The rate of available phosphorus in the soil increased from $20.65 \mathrm{mg} . \mathrm{kg} / \mathrm{soil}$ at P0 to $24.29,27.44$ and $31.62 \mathrm{mg} . \mathrm{kg} / \mathrm{soil} \mathrm{for}$ P50, P75 and P100, respectively with an increase of 53.12\% compared to no addition (P0). There was no significant difference for the bilateral interaction between the inoculation type and the phosphorus levels on the available phosphorus in the soil after planting.

The ability of phosphate dissolving bacteria to produce phosphatase enzymes works to connect the ester bonds that bind phosphorus to carbon, of organic matter, through the release of phosphates which can be taken by organisms that dissolve phosphates and then transfer them to the plant or, by producing lower molecular weight organic acids. like oxalic acid which increases the availability of the soil for phosphorous by increasing the weathering rates in the clay minerals in which phosphorus is present or through the composition of complexes positively charged with $\mathrm{Ca}, \mathrm{Fe}$ and $\mathrm{Al}$ (Al-Hadethi \& Al-Azawi, 2014). It also noted a superiority in the values of the increase in available phosphorous after planting in the treatments inoculated with mutagenic bacteria, compared to the treatments inoculated with wild bacteria. This is due to the role of mutagenic bacteria which dissolve the phosphates through induced mutations that stimulated the production of many 
organic acids in various quantities, which contributed to the reduction of soil $\mathrm{pH}$ and among the most important acids like citric, oxalic, formic, maleic acid and others, as well as the secretion of enzymes in large quantities such as phytase and phosphatases, which increase the level of dissolved phosphorus in soils poor with the phosphorous, such as calcareous soils.

Table 5: Effect of inoculation with B. polymyxa, wild, mutagenic and mixing them together, and levels of phosphate fertilization in available phosphorus after planting (mg.kg/soil).

\begin{tabular}{|c|c|c|c|c|c|}
\hline \multicolumn{6}{|c|}{ Loamy sandy soil } \\
\hline \multirow{2}{*}{$\begin{array}{c}\text { Bacterial } \\
\text { inoculation }\end{array}$} & \multicolumn{4}{|c|}{ Levels of phosphate fertilization } & \multirow[t]{2}{*}{ Rate } \\
\hline & P0 & P50 & P75 & P100 & \\
\hline B0 & 9.32 & 14.88 & 16.82 & 19.96 & 15.24 \\
\hline BW & 16.58 & 19.65 & 23.32 & 29.11 & 22.16 \\
\hline BM & 20.37 & 25.93 & 29.72 & 34.07 & 27.52 \\
\hline BWM & 22.33 & 25.02 & 31.95 & 35.88 & 28.79 \\
\hline Rate & 17.15 & 21.37 & 25.45 & 29.75 & \\
\hline \multicolumn{6}{|c|}{ Silty clay soil } \\
\hline \multirow{2}{*}{$\begin{array}{c}\text { Bacterial } \\
\text { inoculation }\end{array}$} & \multicolumn{4}{|c|}{ Levels of phosphate fertilization } & \multirow[t]{2}{*}{ Rate } \\
\hline & P0 & P50 & P75 & P100 & \\
\hline B0 & 12.88 & 15.29 & 15.45 & 22.07 & 16.42 \\
\hline BW & 18.67 & 21.87 & 26.74 & 30.11 & 24.34 \\
\hline $\mathrm{BM}$ & 24.72 & 29.81 & 32.04 & 36.31 & 30.72 \\
\hline BWM & 26.34 & 30.2 & 35.55 & 38.02 & 32.52 \\
\hline Rate & 20.65 & 24.29 & 27.44 & 31.62 & \\
\hline \multirow{4}{*}{ RLSD 0.05} & \multicolumn{2}{|c|}{ Texture } & 0.138 & $\begin{array}{c}\text { Texture } \times \text { Type } \\
\text { inoculation }\end{array}$ & $\mathrm{ns}$ \\
\hline & \multicolumn{2}{|c|}{ inoculation type } & 0.276 & Texture $\times$ P Level & 0.684 \\
\hline & \multicolumn{2}{|c|}{ P Level } & 0.276 & $\begin{array}{l}\text { Type inoculation } \\
\times \text { P Level }\end{array}$ & $\mathrm{ns}$ \\
\hline & \multicolumn{3}{|c|}{ Texture $\times$ inoculation type $\times$ P Level } & \multicolumn{2}{|c|}{ ns } \\
\hline
\end{tabular}

As for the inoculated treatments with wild and mutagenic together, the results showed that the high values of available phosphorous in the soil, after planting, were compared with the single inoculation due to the high density of the number of bacteria (the wild and mutagenic) that dissolve phosphates in the soil, which leads to an increase in their activity and vital activities in the soil or the rhizosphere. Thus, promoting growth of plants and increasing phosphorus availbility in the soil after planting. These results are in agreement with Jabbar (2018).

The increase in available phosphorus in the soil, after planting, by increasing the levels of phosphate fertilizer is due to the increase in the concentration of phosphorous in the soil by increasing the addition, the greater the amount of phosphate fertilizer added, which led to the higher concentration of available phosphorus in the soil. These results came in agreement with Al-Jebory (2016). 
The improvement of the growth characteristics of the corn grown in loamy sand soil is due to inoculation with wild and mutagenic B. polymyxa, as this bacteria encouraged the plant to uptake nutrients and water in the calcareous loamy sand soils, present in arid and semi-arid areas. It also noted that the high additives of mineral fertilization levels, such as these calcareous loamy sand soils, do not mean obtaining the maximum production for most of the growth characteristics because the largest amount of this addition is lost without plant benefiting from it, as a result of processes of adsorption, precipitation and leaching with irrigation water. Therefore, adding part of the recommended fertilizer and completing it with a bacterial inoculation with a high specialized capacity, such as mutagenic bacteria, will increase the absorption of nutrients for plant growth. This leads to an increase in the level of fertility of the soils and their production by more than that produced by high fertilizer additives in those soils. The joint inoculation bacteria of wild and mutagenic can be considered as a successful technique to improve and raise the productivity of the soils, because these neighborhoods are based by linking the minutes and increasing their size as a result of absorption of these cells on the surfaces of the atoms about $50 \%$ of the bacterial cells are absorbing the atoms, meaning that the bacteria work to block the sand particles, which is called protein and fiber bridges for polysaccharides, thus holding the nutrients and preventing their loss in sandy soils (Hassan, 2011).

The growth indicators of corn exceeded in the calcareous silty clay soil, compared to the calcareous loamy sand soil, due to the increase in the number of wild and mutagenic bacteria dissolving phosphates that the clay minerals of type 1: 2 with a large surface area. The clay minerals are characterized by the ability to expand, contract and provide opportunity to the availability of the basic requirements of carbon sources, nutrients and water. All of these are factors that encourage the proliferation of wild and mutagenic bacteria dissolving phosphates and the prevalence of their vital activities in addition to their ability to decompose organic materials and supply the plant with the nutrients. Hassan (2011) showed that clay protects the bacteria from conditions, other than appropriateness, such as the lack of humidity, drought and high temperatures. Its positive reflection on the growth indicators of the maize plant, is due to the survival rates of bacteria increase with the increase in the ability of the soil to hold water and the provision of energy requirements, as well as due to the positive charge of the properties of some clay particles which makes them more suitable for the attraction of the bacteria dissolving phosphates. The increase in the percentage of clay by $5 \%$ in the soil is sufficient to encourage an increase in number of $B$. polymyxa due to the absorption of these bacteria by the clay atoms which increases the dissolution rate of calcium phosphates deposited by the production of acids and the availability of chelating groups, and thus increase the rate of release of phosphorus available for absorption by the plant. Therefore, the technique of inoculation with the wild and mutagenic bacteria dissolving phosphates with high efficiency to dissolve the added phosphorous as fertilizer is one of the successful techniques to raise the fertile level of calcareous clay soils and reduce the factors that stabilize, obstruct and prepare 
phosphorus by calcium, aluminum or iron ions. The encapsulation of bacterial cells by the fine clay particles is a barrier to the dimensions of the effect of phosphates dissolved from calcium ions in the soil solution, which increases the readiness of phosphorus for absorption by the roots of plants (Hassan, 2011).

On the other hand, use of wild and mutagenic bacteria phosphate dissolving bacteria with chemical fertilizer is not only an additional preparation of the elements necessary for the plant, but it increases the efficiency of the chemical fertilizer and reduces its negative impact on the environment. This means the possibility of reducing the level of chemical fertilizer by a 50\% and replace it with bacteria that dissolve phosphates. Thus, the cost of the agricultural process can be reduced and the possibility of environmental pollution can be controlled. This is in agreement with Al-Hilfy \& Flayyah (2017) and Mustafa (2019) in reducing 50-75\% of chemical fertilizer at adding biofertilizer to obtain similar results in growth. Haran (2019) concluded that adding the inoculation together with half the recommendation of mineral fertilizer reduced the possibility of damage to plants due to high levels of mineral fertilization.

\section{References}

Abbas, M.H. \& Hameed, M.A. (2006). Improve production of indole-3- acetic acid from two mutant isolates of Trichoderma harzianum by UV radiation. J. Basrah Res. (Sci.), 32(2B): 27-37. (In Arabic).

Al-Atab, S.M.S. (2008). Variation of soil properties and classification in some areas of Basrah governorate. Ph. D. Thesis, Coll. Agric., Univ. Basrah: 208 pp. (In Arabic).

Al-Hadethi, B.A.A. \& Al-Azawi, A.M.S. (2014). The effect of interaction between Mycorrhiza and Aspergillus niger in supporting phosphate rock phosphate in the wheat plant (Triticum aestivum L.) in calcareous soil. Diyala J. Agric. Sci., 6(1): 101-105. (In Arabic).

Al-Hilfy, I.H.H. \& Flayyyah, M.I. (2017). Response of two bread wheat varieties yield to mineral, bio- and organic fertilizers. Iraqi J. Agric. Sci., 48(6): 16611671 (In Arabic). DOI:10.36103/ijas.v48i6\%20B.267.

Al-Jebory, A.K.J. (2016). Isolation of Pseudomonas fluorescens and Bacillus subtilis by PCR and studying the effects by immobilized inoculant in growth and yield of corn (Zea mays L.). Ph. D. Thesis, Fac. Agric., Baghdad Univ.: 154 pp. (In Arabic).

Al-Mousawi, K.A.; Hassan, Z.K. \& Mohammed, H.J. (2017). The effect of the bacterial inoculation on the some physical and chemical properties for sandy soil and corn crop growth parameters (Zea may L.). Assiut J. Agric. Sci., 48(4): 200-215. (In Arabic).

Al-Rawi, K.M. \& Khalafallah, A.M. (2000). Design and analysis of agricultural experiments, $2^{\text {nd }}$ edition. Dar Al Kutub Publ., Univ. Mosul: 474 pp.

Al-Taii, M.A. \& Dhahi, S.J. (2014). The mutagenicity of the fungicides Topsin-M and Rizolex in conidia of the fungus Aspergillus amstelodami. Tikrit J. Pure Sci., 19(6): 73-78. (In Arabic). 
Al-Zougbi, M.M.; Haissam, E. \& Mohammed,E. (2007). Effect of organic and biofertilizers on production of potatoes and on some soil properties in Tartous. Damascus Univ. J. Agric. Sci., 23(2): 151-162.

Amruth, B.; Thippeshappa, G.N.; Gurumurthy, K.T.; Chidanandappa, H.M. \& Sheker, B.C. (2017). Effect of phosphorus levels through integrated nutrient management (INM) packages on phosphorus availability and phosphorus fractions in soil under groundnut crop. Int. J. Curr. Microbiol. Appl. Sci., 6(9): 3398-3404. DOI:10.20546/ijcmas.2017.609.418.

Baker, S.Z.; Hassan, A.A. \& Daham, R.S. (2019). Quantitative propagation of local isolatesof Beauveria bassiana and Metarhizium anisopliae and improvement their bio-efficacy by ultra-violet irradiation. J. Kirkuk Univ. Agric. Sci., 10(1): 154-165. (In Arabic).

Black, C.A. (1965). Methods of soil analysis, Part2. Agronomy 9 ASA/SSSA, Madison: $840 \mathrm{pp}$.

Bremner, J.M. \& Edwards, A.P. (1965). Determination and isotope-ratio analysis of different forms of nitrogen in soils: I. Apparatus and procedure for distillation and determination of ammonium. Soil. Sci. Soc. Amer. J., 29(5): 504-507. DOI: $10.2136 /$ sssaj1965.03615995002900050011x.

Chaichi, M.R.; Shabani, G. \& Noori, F. (2015). Response of berseem clover (Trifolium alexandrinum L.) to chemical, biological and integrated use of fertilizers. Cercetari Agron. Moldova, XLVIII1(1, 161): 77-87.

Fincheira-Robles, P.; Martinez-Slgado, M.M.; Ortega-Blu, R. \& Janssens, M. (2016). Compost and humic substance effects on soil parameters of Vitis vinifera L. cv Thompson seedless. Sci. Agropecu., 7(3): 291-296.

Haran, M.S. (2019). Effect of single and mixture inoculation with phosphate solubilizing bacteria (Bacillus spp.), Azotobacter and $P$. florescence in growth and yield of corn Zea mays L. irrigated with different saline water. Ph. D. Thesis, Coll. Agric., Univ. Basrah: 170 pp.

Hassan, A.A. (2015). Improvement of antagonism and fungicides tolerance in Trichoderma harzianum and $T$. viride local isolates by ultra-violet irradiation. Tikrit J. Pure Sci., 20(4): 16-25.

Hassan, Z.K. (2011). Isolation and diagnosis of Azospirillum lipoferum and Bacillus polymxa from some soils in southern Iraq and their role in biological fertilization of yellow corn plants (Zea mays L.). Ph. D. Thesis, Coll. Agric., Univ. Basrah: 220 pp. (In Arabic).

Jabbar, A.K. (2018). Influence of biological inoculant of Paenibacillus polymyxa on available phosphorous from phosphorous rock on growth and yield of Zea mays L. Al-Muthanna J. Agric. Sci., 6(2): 9-19. (In Arabic).

Jackson, M.L. (1985). Soil chemical analysis: Advanced course, $2^{\text {nd }}$ edition. Parallel Press, Madison, Wisconsin: 929 pp.

Jasim, H.M. \& Thiab, R.S. (2009). Effect of some physical mutagens on Pseudomonas aeruginosa $\mathrm{H} 3$ in alginate production. J. Biotechnol. Res. Cent. (Spec. Edition), 3(2):13-22. 
Mengel, K. \& Kirkby, E.A. (2001).Principles of plant nutrition, $5^{\text {th }}$ edition. Springer, Netherlands: xxvi + 849 pp. DOI:10.1007/978-94-010-1009-2.

Mustafa, M.J. (2019). Effect of phosphorus fertilizers through integrated nutrient management on some soil properties and growth of sunflower (Helianthus annuus L.). M. Sc. Thesis, Coll. Agric., Univ. Basrah: 130 pp. (In Arabic).

Naser, K.M. (2016). Kinetics of phosphorous release from added rock phosphate with some organic fertilizers on calcareous soil. Iraqi J. Agric. Sci., 47(5): 1305-1311. (In Arabic).

Page, A.L.; Miller, R.H. \& Kenney, D.R. (1982). Methods of soil analysis, Part 2. Chemical and biological properties, $2^{\text {nd }}$ edition. Am. Soc. Agron., Madison, Wisconsin: 1158 pp. DOI:10.1002/jpln.19851480319.

Richa, G.; Khosla, B. \& Reddy, M.S. (2007). Improvement of maize plant growth by phosphate solubilizing fungi in pock phosphate amended soils. World J. Agric. Sci., 3(4): 481-484.

Richards, L.A. (1954). Diagnosis and improvement of saline and alkali soils. U.S. Dept. Agric. H.B. No. 60: 160 pp.

Sumalatha, G. \& Jebarathnam, T.G. (2018). Integrated nutrient management in sunflower with apiary farming system. J. Adv. Stud. Agric, Biol. Environ. Sci., 5(2): 1-6.

Turki, A.M.; Abdul Ratha, H.A. \& Ali, N.A.H. (2010). The bio role of genetically modified Azotobacter. Iraqi J. Biotechnol., 9(3): 310-320. (In Arabic). 